\title{
Estética, política e cidades: apontamentos sobre a dimensão crítica de intervenções artísticas em espaço urbano no final do século $X X$
}

\section{Gabriel Girnos Elias de Souza}

Arquiteto e urbanista, professor assistente efetivo no Departamento de Arquitetura e Urbanismo da Universidade Federal Rural do Rio de Janeiro (UFRRJ), Rua Honório de Barros n²8, apto 502, Flamengo, Rio de Janeiro - RJ, CEP 22250-120, (21) 3258-3347, gabrielgirnos@gmail.com

\begin{abstract}
Resumo
O artigo traça um panorama de questões e referências sobre arte, política e espaço urbano na contemporaneidade. Começa com os aspectos de despolitização e estetização da cidade, com destaque à exploração da cultura como marketing e controle; em seguida são discutidas as dimensões políticas da arte no século XX, para então delinear algumas formas básicas de operações críticas sobre o espaço urbano desenvolvidas desde os anos sessenta. Por fim, é introduzida a particularidade dos grandes eventos de arte em espaços urbanos e as dificuldades que a rotineirização institucional da transgressão cria para a dimensão crítica da arte na cidade.
\end{abstract}

Palavras-chave: arte urbana, espaço urbano, cultura. final do século XX assistiu à proliferação de uma série de iniciativas artísticas de ida ao espaço urbano, incluindo desde intervenções isoladas a grandes eventos expositivos, as quais conviveram com um crescente valor estratégico da produção artística e cultural em políticas urbanas de desenvolvimento e atração de capital e mercados. Este fenômeno, já bastante estudado, estaria por sua vez ligado de forma geral a um processo mais amplo de transbordamento da estética e de encolhimento da política nos tempos recentes — imbricados ao domínio progressivo de relações de mercado sobre as variadas dimensões da vida humana - e também à busca pela reorganização de propostas políticas e estéticas de resistência a partir dessa realidade.

As mudanças profundas e aceleradas na tecnologia, economia e cultura do final de século XX marcaram um deslocamento de posição e significado para certas noções políticas básicas da modernidade ocidental como Estado, classe, trabalho, esfera pública, subjetividade e história — numa situação que vários autores designariam como "pós-modernidade" 1. Na visão de alguns pensadores, ao final do século XX a política seria crescentemente substituída pelas relações de mercado e, no limite, pela ideia de uma administração eficiente da vida. Esse esvaziamento implicaria numa crise da inserção social do discurso crítico, nisso incluso o teor crítico e político das manifestações estéticas como um todo.

O filósofo Jacques Rancière pensou tal situação contrapondo os conceitos de política e polícia e de consenso e dissenso. A "política", segundo sua concepção, estaria fundamentada no dissenso: não apenas um conflito de interesses de grupos distintos mas, mais profundamente, a possibilidade de opor diferentes configurações do mundo sensível. "Polícia", por sua vez, denominaria o que banalmente se tem por "política" em nossa ordem cotidiana: as atividades de administração, agregação, vigilância e manutenção da ordem fundamentadas no consenso, 
um modo de simbolização da comunidade que visa excluir aquilo que é o próprio cerne da política: o dissenso [...]. O consenso tende a transformar todo conflito político em problema que compete a um saber de especialista ou a uma técnica de governo. Ele tende a exaurir a invenção política das situações dissensuais. (RANCIÈRE, 2005)

A verdadeira racionalidade da política, assim, afirmaria a cisão estrutural da sociedade, um mundo comum "instituído, tornado comum, pela própria divisão" (RANCIÈRE, 1996, p.368). Nessa compreensão de política como um conflito sobre a partilha do mundo sensível, as múltiplas formas de elaboração estética, como construções do sensível, carregam necessariamente sempre dimensões políticas, participando sutil e inelutavelmente na formação de consensos e dissensos.

Tendo então como inquietação de fundo a produção estética como fator tanto de politização como de despolitização do espaço urbano contemporâneo, este texto tem o objetivo de delinear um panorama de questões e referências de pensamento sobre as relações políticas entre arte e cidade no final do século passado, o qual possa servir a análises e reflexões futuras sobre iniciativas de arte urbana. Para tanto, começaremos pela questão de despolitização da cidade e da estética, visitando a noção de espetacularização e a instrumentalização da cultura em políticas urbanas. Em seguida será introduzida a questão do relacionamento entre arte e política; passando-se logo à discussão específica das possibilidades de atuação da arte na cidade, serão delineadas quatro direções básicas de intervenção crítica vistas nas últimas décadas. Por último, o potencial crítico das práticas de intervenção será questionado diante do contexto de espetacularização discutido antes e da institucionalização das transgressões artísticas; aqui se dará especial atenção ao fenômeno particular dos grandes eventos de arte urbana, compreendidos como uma tendência tão significativa quanto problemática na arte urbana recente.

\section{Metrópole: despolitização e estetização}

Ambiente construído pela coletividade humana e lugar de adensamento e produção de cultura e história, a cidade é classicamente concebida como lugar da política, sendo vital ao horizonte civilizador da modernidade e à idéia de democracia e de espaço público. As experiências urbanas do cosmopolitismo, da diferença e da multidão seriam constituintes da esfera pública moderna. Em contraponto ao arbítrio e interesse despótico da esfera privada, o mundo público urbano seria o solo da experiência da alteridade, do encontro com o estranho: o lugar, enfim, da possibilidade de eqüidade na diferença e da constituição do dissenso.

Desde o surgimento das metrópoles da era industrial, porém, a grande cidade também figurou como lugar inóspito de incivilidade, desigualdade e insalubridade; o lugar onde se produz alienação. O olhar sobre esse aspecto fragmentador da sociabilidade, da percepção e da política se impõe com tanto mais força em megalópoles da periferia do capitalismo "pós-industrial", como São Paulo, Rio de Janeiro ou Cidade do México.

A metrópole contemporânea se despolitiza por ser ininteligível: por demais extensa, complexa e fragmentária, ela é inapreensível como totalidade. Marcada pela expansão, pela descontinuidade, pelo ruído e pela transformação constante aspectos ligados à expansão exagerada ocorrida sob a primazia de lógicas privadas como as do mercado imobiliário ou do automóvel - a estrutura urbana passa a ser determinada "mais pela continuidade topológica das infraestruturas do que pelo padrão geométrico do tecido urbano" (ZAERA, 1996, p.13). Um território em constante crescimento e reconstrução, ao mesmo tempo pontuado por terrenos, edifícios e espaços públicos em abandono, desconectados do sistema produtivo e do uso cotidiano dos habitantes. A opacidade de sua configuração e funcionamento reduz a cidade a um conjunto de problemas intrincados, e tende a reduzir a política à administração e aplicação eficiente de conhecimentos técnicos.

A metrópole se despolitiza também ao perder gradualmente sua característica de lugar de socialização. O espaço público se torna primariamente espaço de circulação; as distâncias aumentam bruscamente, os espaços são rasgados e descaracterizados para dar vazão ao tráfego; o espaço urbano passa a ser caminho a ser cruzado entre os ambientes privados da casa, do trabalho ou da diversão, gerando uma convivência pública 
cada vez mais exígua e socialmente homogênea. A comunicação e convivência se privatizam de maneira crescente, seja através de meios de telecomunicação, seja nos espaços privados que simulam imagens de "urbanidade" — condomínios fechados, enclaves empresariais, centros comerciais — ou em espaços públicos devidamente vigiados, livres das atividades informais de populações mais pobres. Nessa privatização do convívio, é corroído o poder da experiência urbana como encontro com a alteridade. O espaço de megalópoles como São Paulo, Los Angeles (E.U.A.) ou Lagos (Nigéria) expressa, materializa e reproduz uma cisão social em que a cidade como espaço público, político e coletivo encontra dificuldade em acontecer; esta deixa de ser o lugar histórico e simbólico da civilidade para converter-se em local de marginalidade, da violência e perigo, onde a política confunde-se crescentemente com a gestão da segurança.

A metrópole se despolitiza por sua mercantilização. No contexto recente da globalização e financeirização da economia - assim como da crescente importância do turismo como gerador de divisas - as metrópoles tornam-se pontos estratégicos da circulação econômica mundial, o que também cria um clima de competição pela atração de empresas, investimentos e turistas. Em meio a tal situação, a dimensão da cidade como lugar civilizador da coletividade seria superada por seu papel como espaço de investimento e lucro; sua dimensão identitária e formativa, subordinada ao fornecimento de possibilidades de consumo e prazer. As cidades se assemelhariam cada vez mais a empresas e mercadorias: algo a ser administrado, vendido e consumido, visando à produção crescente e competitiva de lucro. A política, assim, é substituída pelo gerenciamento eficiente e pelo consumo.

Por fim, a metrópole se despolitiza pela estetização. Seja nos meios de comunicação simplesmente inseparáveis da vida atual, seja na ubiqüidade de imagens de publicidade em toda e qualquer superfície visível, seja no embelezamento e design dos objetos e espaços do espaço urbano, a percepção da cidade contemporânea está sempre rodeada pela produção técnica de aparências e representações. Concomitantemente, pode-se dizer também que as dimensões sensíveis e simbólicas ganham um papel crescentemente compensatório e paliativo num espaço urbano que dificulta vínculos, fragmentário e agressivo aos sentidos, socialmente dividido, crescentemente privatizado e direcionado pelo lucro financeiro. Na confluência do desejo por segurança, inteligibilidade e identidade coletiva com a necessidade de criação de cenários urbanos e imagens positivas para a atração de empresas, turismo e mercados, a estética é mobilizada tanto como dimensão reconciliadora quanto como fator estratégico de valorização mercantil.

\section{Estética e espetáculo}

Quais as implicações propriamente políticas da estetização generalizada da realidade material das cidades? Há décadas são estudadas e discutidas as conexões entre o processo de midiatização e estetização e as transformações do sistema capitalista de consumo, e como elas afetam a relação fundamental dos agentes humanos com a produção de sua realidade sensível. A noção de espetacularização é com frequência invocada nesse debate, em geral ligada ao conceito seminal de espetáculo formulado por Guy Debord em fins dos anos sessenta: uma "relação social mediada por imagens" que institui um consumo passivo e contemplativo como modelo sociocultural dominante.

O espetáculo [...] não é um complemento ao mundo real, um adereço decorativo. É o coração da irrealidade da sociedade real. Sob todas as suas formas particulares de informação ou propaganda, publicidade ou consumo direto do entretenimento, o espetáculo constitui o modelo presente da vida socialmente dominante. Ele éa afirmação onipresente da escolha já feita na produção, e no seu corolário - o consumo. (DEBORD, 1997)

Na esteira dessa e outras críticas socioculturais de fundo marxista, vários autores nas décadas seguintes já desenvolveram o problema da espetacularização em termos de uma irrealização da vida urbana contemporânea: um processo de reprodução de uma alienação em relação à realidade social, na qual os meios de comunicação, a publicidade e o embelezamento forneceriam sucedâneos dos vínculos culturais perdidos no próprio processo de mercadorização da vida. Como resume o crítico Hal Foster:

no espetáculo, o "desejo das massas contemporâneas de ter as coisas mais 'próximas' espacial 
2 No trecho entre aspas, Hal Foster faz uso de palavras de Walter Benjamin

3 Chauí relembra que as palavras "espetáculo" e "especulação" têm a mesma origem, "e estão ligados à ideia do conhecimento como operação do olhar e da linguagem. A cultura está impregnada de seu próprio espetáculo, do fazer ver e do deixar-se ver" (CHAUÍ, 1993).
3 Chauí relembra que as palavras "espetáculo" e "especulação" têm a mesma origem, "e estão ligados à ideia do conhecimento como operação do olhar e da linguagem. A cultura está impregnada de seu próprio espetáculo, do fazer ver e do deixar-se ver" (CHAUÍ, 1993). e humanamente" - de superar a alienação - é preenchido de maneira falsa exatamente porque o que é oferecido é o próprio oposto da comunidade, o próprio instrumento da alienação: a mercadoria. [...] Desse modo, o espetáculo representa "o ponto em que a aparência estética se torna uma função da natureza da mercadoria"; na verdade, no espetáculo, a aura perdida da arte, da tradição, da comunidade, é substituída pela "aura" da mercadoria. (FOSTER, 1996$, p. 130 $)^{2}$

Na ubiquidade da produção técnica de aparências com vistas à sedução, portanto, a estética confundirse-ia cada vez mais com a fetichização; propensa a nivelar tudo como opção de consumo, por um lado, e a prometer satisfações e felicidades fora do alcance, por outro, a estetização da cidade seria, paradoxalmente, a um só tempo uma tentativa de resposta à irrealização da vida urbana e um componente ativo dessa mesma irrealização.

A estilização ou estetização generalizada é a resposta da megalópole para a angústia gerada pela falta do objeto, e é o modo através do qual denega o niilismo que ela mesma difunde. Veiculada pela mídia e pelo próprio habitat que se faz emissor e receptor de imagens, a estetização propõe ao habitante um infindável desfile de estilos que ele compra, acreditando poder satisfazer uma demanda na realidade insaciável, porque é uma demanda inconsistente. (SANTOS, 1994)

Nessa linha de pensamento, a "irrealização" espetacular representaria a captura da dimensão estética num registro inerentemente despolitizador. Refletindo especificamente sobre o peso da dimensão estética no espaço urbano contemporâneo na década de noventa, autores como V. Pallamin já colocaram que, nesse contexto recente de privatização econômica e desinvestimento simbólico dos espaços públicos, a própria recepção estética tenderia a portar e reproduzir "um sentido de contínuo desenraizamento", concomitante a uma crescente "desafeição por metas coletivas" (PALLAMIN, 2001, p.69-70)

Em seu sentido amplo, a ideia de espetáculo frequentemente carregou potencialidades políticas, com um grande poder de transgressão e mobilização coletiva na história humana3; o que estaria em jogo aqui, então, seria a substituição da potência do espetáculo como forma de resistência por seu poder como forma de controle social (ARANTES, 2002, p.62).

\section{Cultura e cidade: propaganda, disputa e "conciliação"}

A estetização espetacular da cidade está imbricada a uma profunda instrumentalização da cultura. Em definição bem ampla, "cultura" poderia ser compreendida aqui como o conjunto de práticas pelas quais seres humanos se humanizam, criando sua existência social, econômica, política, religiosa, intelectual e artística (CHAUÍ, 1995, p.295). No referido contexto de predomínio da estetização consumista, entretanto, as conotações de "cultura" tendem a se confundir crescentemente com entretenimento, embelezamento e distinção social, tendo seu caráter dissensual diluído e passando a fazer parte dos processos de apropriação e mercadorização do espaço urbano.

[...] este transbordamento do estético, sendo concomitante a um crescente desinteresse pelo político, traz em seu bojo os dilemas da dilapidação de ações culturais concorrendo para sua "funcionalização". A cultura, nesses termos, é reduzida às consequências das mudanças econômicas e a mercadificação de projetos e práticas culturais Ihes acarreta uma perda de seu potencial de contribuição para com uma tarefa social na qual a dignidade humana seria privilegiada na vida do mais amplo coletivo. (PALLAMIN, 2001, p.77-78)

De um ponto de vista histórico, o contexto aqui esboçado de apropriação da estética e da cidade através da estética estaria relacionado às novas relações entre políticas urbanas e políticas culturais estabelecidas no fim do século XX. Em meio à proliferação de lugares genéricos, de espaços degradados e esvaziados de uso e sentido e à presença crescente de populações "não integradas", o âmbito cultural tornou-se depositário de esperanças de "reconciliação" com a cidade.

Desde o fim dos anos setenta, as mudanças econômicas e políticas da globalização e da "pósmodernidade" esboçaram um novo tipo de atuação sobre centros urbanos, marcado por "revitalizações" de áreas centrais degradadas, gradualmente abandonadas na reorganização espacial da produção 
econômica industrial e na ida da moradia e atividade das elites para outros locais. No lugar do ideário de planejamento global, estabeleceu-se então um modelo calcado no desenvolvimento de mercado, com intervenções pontuais e estratégicas que visariam servir de motor para a valorização de determinadas áreas perante o mercado e os habitantes. Atividades culturais adquiriram grande importância nessas novas estratégias, em que convergiam interesses estatais e privados na projeção de uma imagem de prestígio e bem-estar social que contribuísse no desenvolvimento do turismo e do mercado imobiliário. Assim, instalou-se uma busca pela constituição de um

4 Entre os casos pioneiros de revitalização cultural de áreas degradadas, poderiam ser citadas aqui a implantação do Centro Georges Pompidou em Paris e a recuperação de regiões "perigosas" ou "decadentes" de Nova York como o Soho e East Village através de sua transformação em centros de arte contemporânea. No Brasil, um dos primeiros e mais significativos exemplos de reforma urbana "cultural" estaria na reforma do bairro histórico do Pelourinho, na cidade de Salvador - que, iniciada em 1992. "literalmente 'limpou' o sítio histórico ao expulsar seus habitantes e suas respectivas práticas cotidianas populares e substituí-las por 'simulacros culturais turísticos'" (JACQUES, 2005).

5 Entre nossas referências de estudos sobre gentrifications e sobre o uso de discursos de coesão social, estariam as considerações de D. Harvey sobre a Baltimore City Fair de 1970: um tipo de resposta administrativa ao acirramento de distúrbios e conflitos urbanos da década de 60 , com estratégias visando maneiras de "reunir" a cidade, "promover o redesenvolvimento urbano" e superar a "mentalidade de cerco com que o cidadão comum encarava o centro da cidade" (HARVEY, 1993, p.89). Outro exemplo seria o estudo da crítica norte-americana Rosalyn Deutsche sobre a requalificação da Union Square Garden, onde as populações "indesejáveis" de mendigos teriam sido afastadas em nome da "integridade do espaço público" e da "união cívica" — representada entre outras coisas, pelas esculturas comemorativas do local (DEUTSCHE, 1996). clima de "urbanidade", em geral expresso na busca de ambientes social e esteticamente harmônicos que evocassem prosperidade, entretenimento, cosmopolitismo e aculturação. Entre os vários tipos de renovação "cultural" resultantes nas últimas décadas, Vaz e Jacques listam

desde a tradicional reabilitação de centros antigos com preservação de patrimônio histórico; passando pela renovação de áreas degradadas nas quais incorporadores se utilizavam de museus e equipamentos de lazer para aumentar os valores imobiliários; pela reabilitação de áreas centrais que se tornaram quase shoppings a céu aberto; pela recuperação de centros históricos que se tornam vastos museus; pela requalificação de ambientes históricos que evocam cenários padrão Disneyland; até a promoção de nova imagem local apoiada em novos ícones arquitetônicos. (VAZ e JACQUES, 2003, p.132)

A constituição de uma imagem simbólica e economicamente atraente para as cidades também exigiria manter um clima de "agitação cultural" (ARANTES, 2002), manifestada na proliferação de centros e instituições culturais - frequentemente ligadas a instituições financeiras - mas também de uma igualmente importante ampliação do circuito temporário de exposições, espetáculos, oficinas, festivais, eventos e das novas megaexposições internacionais. Nesse processo, a própria cidade se aproximaria de um imenso museu-espetáculo, ofertando atrações de cultura, lazer e turismo.

Essa constituição estetizante de uma nova "urbanidade", por sua vez, guardaria relação com o crescimento da violência e marginalidade sociais. Um aspecto ressaltado por muitos estudos das "revitalizações" ou "requalificações" de áreas centrais degradadas seria o fenômeno denominado gentrification: processo no qual populações de baixo poder aquisitivo - as mais temidas pelo pânico social - dariam lugar a populações economicamente mais "interessantes". Com facetas e manifestações particularizadas em várias cidades do mundo, tal processo teria tanto mecanismos jurídicos, econômicos (alta de aluguéis, expropriação ou expulsão, etc.) e policiais (arquiteturas "antimendigo", vigilância, etc.) quanto elementos simbólicos - como o estabelecimento de arquiteturas de acesso controlado ou que, apesar de publicamente acessíveis, sejam socialmente "intimidadoras" por sua monumentalidade e caráter "de elite". Devido a sua conotação de "distinção", por sua vez, o emprego generalizado da estética e da cultura estaria justamente relacionado a esse aspecto simbólico e segregador de "enobrecimento" 4 .

Diante desse quadro de exclusão e disputa do espaço, autores como David Harvey e Rosalyn Deutsche viram na "culturalização" da política urbana uma proposta implícita de "concretizar" simbolicamente uma integração social e uma cidadania inexistentes - proposta que, na verdade, legitimaria a segregação e a privatização da cidade ${ }^{5}$. A intenção "harmonizadora" do investimento em cultura e arte tenderia então a ser ideológica, no sentido marxista do termo: um discurso que "oferece à sociedade fundada na divisão e na contradição interna uma imagem capaz de anular a existência efetiva da luta, da divisão e da contradição" (CHAUÍ, 2003, p.27). Assim, embora em geral autoproclamadas "democráticas", as estratégias ligando a imagem positiva da cidade com o "bem público" e a coesão social na verdade tenderiam a ser policiais: ações e discursos reforçadores de consensos e contrários ao dissenso constitutivo do espaço verdadeiramente político.

\section{"Terrain Vague"}

Para além dos esforços e discursos voltados a uma urbanidade "harmoniosa" e à reinserção das áreas residuais e degradadas da cidade numa matriz de identidade urbana, todavia, os anos noventa também veriam o estabelecimento de um campo de leituras, discussões e iniciativas mais especulativas a respeito desses espaços, influenciadas por expoentes da filosofia e arte contemporânea. Essas atividades 
procurariam tratar a cidade justamente em sua dimensão de fragmentação, voltando-se a princípio menos a recuperar uma coesão do que a refletir e elaborar sobre as potencialidades mnemônicas e estéticas dos vazios urbanos enquanto espaços de alteridade, deslocados do sistema econômico e simbólico da cidade.

Estes lugares estranhos existem a parte dos circuitos 6 Na versão original: "These strange places exist outside the city's effective circuits and productive structures. From the economic point of view, industrial areas, railway stations, ports, unsafe residential neighborhoods, and contaminated places are where the city is no longer. [...] What is to be done with these enormous voids, with their imprecise limits and vague definition? Art's reaction, as before with "nature" (which is also the presence of the other for the urban citizen), is to preserve these alternative, strange spaces, strangers to the productive efficiency of the city. If in ecology we find the struggle to preserve the unpolluted spaces of a nature mythicized as the unattainable mother, contemporary art seems to fight for the preservation of these other spaces in the interior of the city" (SOLÀMORALES, 1995, pp.40-41).

7 Solà-Morales explicaria da seguinte maneira a preferência pelo termo francês: "tanto la noción de 'terrain' como la de 'vague' contienen una ambigüedad y una multiplicidad de significados que es la que hace de esta expresión un término especialmente útil para designar la categoría urbana y arquitectónica con la que aproximarnos a los lugares, territorios o edificios que participan de una doble condición. Por una parte 'vague' en el sentido de vacante, vacío, libre de actividad, improductivo, en muchos casos obsoleto. Por otra parte 'vague' en el sentido de impreciso, indefinido, vago, sin límites determinados, sin un horizonte de futuro" (SOLÀMORALES, 1996. p.10-23). efetivos da cidade e de suas estruturas produtivas. Do ponto de vista econômico, áreas industriais, estações de trem, portos, bairros residenciais inseguras, e lugares contaminados estão em locais onde a cidade não mais está. [...] O que deve ser feito de vaga definição? [...] a reação da arte é preservar estas alternativas, espaços estrangeiros, estranhos para a eficácia produtiva da cidade. Se na ecologia encontramos a luta por preservar os espaços despoluídos de uma natureza mitificada como mãe intocada, a arte contemporânea parece lutar pela preservação destes outros espaços no interior da cidade. (SOLÀ-MORALES, 1995, pp.40-41) ${ }^{6}$

Crescentemente presente nas artes desde os anos setenta, esse outro olhar ao urbano tornou-se foco de um debate mais articulado no pensamento sobre a cidade de meados dos anos noventa — época em que o arquiteto e filósofo Ignasi de Solà-Morales fez uma das formulações mais influentes do tema, cunhando a expressão Terrain Vague ${ }^{7}$. Atingindo considerável relevância então — chegou a ser um dos cinco pontos de discussão do Congresso Mundial de Arquitetura de 1996, em Barcelona (FIORAVANTE, 06 jul. 96) — os debates e reflexões sobre vazios urbanos foram tema de várias iniciativas artísticas desde então (no Brasil, o Projeto Arte/Cidade, foi provavelmente o exemplo mais significativo de manifestações relacionadas ao tema).

Contudo, mesmo para se pensar essa outra abordagem cultural sobre a cidade é preciso considerar sua convivência com um contexto de predominância de concepções "essencialistas" do espaço urbano como lastro físico de uma comunhão cívica; um contexto no qual estética e cultura, crescentemente "funcionalizadas", teriam conotações de autonomia e transcendência em relação aos conflitos da sociedade. Nesse registro, como apontaram autores como Arantes e Rancière, se operaria uma substituição da ação e reivindicação com estes enormes vazios, de limites imprecisos e política pela ação e inclusão "culturais". A cultura, assim, seria a "cola social" (HARVEY, 1993) a levar beleza ao feio, poesia ao desencantado, vida ao decadente, identidade ao vago, diversidade ao genérico, civilidade ao incivilizado, bem como também alguma inclusão aos excluídos — seja por proporcionar-lhes acesso à "alta cultura", seja por colocar em evidência a cultura produzida por estes, seja por "gerar renda" para estes. Nas políticas urbanas e culturais brasileiras dos fins do século, por exemplo, foi comum que estética e cultura adquirissem essa conotação de "panacéia" para patologias urbanas e sociais, sendo vinculadas a discursos de "democratização do acesso à cultura" e depois mesmo à valorização da cultura "de periferia".

No contexto dessa cooptação política e comercial da produção cultural, a pergunta que se coloca é se tanto as faces mais conservadoras da produção cultural ("democratização" da "alta cultura", nostalgia de um espaço público idealizado, etc.) quanto as mais progressistas (valorização de culturas "alternativas" ou dos potenciais próprios dos terrain vagues) não acabariam sendo constituídas e apropriadas no interior de uma ordem de espetáculo, consumo e apaziguamento de conflitos; e como elas poderiam, por ventura, evitá-lo.

\section{Arte, crítica e cidade}

Colocadas as questões de despolitização e espetacularização sobre a cidade e cultura é necessário redirecionar o foco desta reflexão para as especificidades das atividades artísticas - ala específica da produção cultural geral — e sua relação política com o espaço urbano, em especial em suas manifestações de intervenção sobre este.

De início, é necessário revisitar a própria noção de arte como uma atividade crítica e política. De uma maneira geral, pode-se dizer que "a Arte" aparece no imaginário da modernidade com uma ruptura no reino das "artes" — o reino das técnicas, das formas do fazer - que separaria a esfera das artes práticas utilitárias, do labor, e a esfera "autônoma" das "belas-artes", território da expressão e representação estéticas. Antes dotadas também de funções utilitárias e ritualísticas, as "obras de arte" na modernidade seriam despojadas de "suas antigas funções de ícones da fé, de emblemas do poder 
80 regime estético das artes seria "um determinado regime de liberdade e de igualdade das obras de arte, em que estas são qualificadas como tais não mais segundo as regras de sua produção ou a hierarquia de sua destinação, mas como habitantes iguais de um novo tipo de sensorium comum onde os mistérios da fé, os grandes feitos dos príncipes e heróis, um albergue de aldeia holandesa, um pequeno mendigo espanhol ou uma tenda francesa de frutas ou de peixes são propostas de maneira indiferente ao olhar do passante qualquer, o que não quer dizer à totalidade da população, todas as classes confundidas, mas a esse sujeito sem identidade particular chamado 'qualquer um'" (RANCIÈRE, 2005). ou de decoração da vida dos Grandes" (RANCIÈRE, 2005) para serem objetos de contemplação estética e passarem a pertencerem a uma instituição social específica. Essa "partilha do sensível" característica da modernidade - que Rancière denominou regime estético das artes ${ }^{8}$ — não desvinculou a arte de seu lugar como signo de sofisticação e distinção social das elites; mas iria Ihe possibilitar o questionamento a respeito do que é ou não assunto desta, do que é ou não próprio de seu fazer e por quem e para quem essa arte é feita.

Condição problemática e parcial desde o princípio, a "autonomia" da esfera artística em relação à "vida prática" viria instaurar no interior da arte moderna uma tensão permanente entre as duas partes cindidas. A busca pela reaproximação entre "vida" e "arte" foi uma característica essencial das vanguardas modernistas do século XX: desde o período entre guerras, manifestações vanguardistas buscariam questionar a arbitrariedade da "autonomia" e do valor social da arte, por um lado, ou estabelecer uma relação de aprendizado e ensinamento com a vida, por outro. Rejeitada como "esfera autárquica" (FOSTER, 1996, p.20) por muitos no século XX, entretanto, a arte não seria apenas mais um elemento da vida; grosso modo, a utopia vanguardista de "fusão da vida à arte" teria como ideal de futuro trazer a essa mesma vida a autonomia e "transcendência" da arte. No bojo das mudanças intensas do espaço, modos de vida e percepção do século XIX e XX, a prática da arte se firmou como possível instrumento de compreensão e proposição das novas formas de percepção e prática que expressariam e moldariam o mundo novo - o que implica também na arte como uma prática crítica às percepções e aos modos de vida da sociedade.

O mote do modernismo foi a grande frase da crítica do jovem Marx a Hegel: modernistas acreditavam que era necessário para qualquer arte [...] tomar as formas do presente profundamente dentro de si, com o risco de mímica, quase ventriloquia; mas disso poderia vir a possibilidade de crítica, de verdadeira desestabilização - iriam "ensinar às formas petrificadas como dançar cantando-Ihes sua própria música". (CLARK, 2002)

Assim, de esfera de distinção social e representação de poderes instituídos, a arte passou a ser pensada como potência transformadora da realidade — ou seja, pensada em sua presença política. Nesse caminho, entretanto, entrariam em conflito dois aspectos básicos: "a autonomia da forma (custodiada pela aura) e a pressão dos conteúdos históricos (marcada pela utopia)" (ESCOBAR, 2002, pp.3435). Essa diferença viria a definir o que poderia ser resumido aqui como dois aspectos de crítica perpetrada pela arte: por um lado, a exploração das formas da percepção e expressão humanas interiores à própria arte - uma direção de "afastamento" em relação à "vida prática" ou, ao menos, de manutenção de uma diferença essencial entre "arte" e "vida"; e por outro, a busca pela crítica ou intervenção direta nos conteúdos, símbolos e fazeres da "vida prática" — um movimento de aproximação e sobreposição à vida. Obviamente, tal divisão não significa uma divergência obrigatória; certas obras desafiam uma distinção simplista, movendo-se criticamente em múltiplas dimensões. Tampouco é simples falar de qualquer hierarquia de potencial "político" entre esses dois caminhos. Segundo Rancière, a dimensão política da arte não estaria propriamente em sua capacidade de "explicar" o mundo, mas em promover o choque entre realidade e potencialidade; para o autor, o realmente político não seria "o conhecimento das razões que produzem tal ou tal vida, mas o confronto direto entre uma vida e o que ela pode" (RANCIÈRE, 2005).

[...] a arte não é política antes de tudo pelas mensagens que ela transmite nem pela maneira como representa as estruturas sociais, os conflitos políticos ou as identidades sociais, étnicas ou sexuais. [...] Porque a política, bem antes de ser o exercício de um poder ou uma luta pelo poder, é o recorte de um espaço específico de "ocupações comuns", é o conflito para determinar os objetos que fazem ou não parte dessas ocupações, os sujeitos que participam ou não delas, etc. Se a arte é política, ela o é enquanto os espaços e os tempos que ela recorta e as formas de ocupação desses tempos e espaços que ela determina interferem com o recorte dos espaços e dos tempos, dos sujeitos e dos objetos, do privado e do público, das competências e das incompetências, que define uma comunidade política. (RANCIĖRE, 2005)

O interesse específico do presente texto, por sua vez, está nas questões políticas e estéticas que se colocam formas de arte que, de diferentes maneiras, acabam por construir-se em sobreposição ao "espaço 
da vida" - mais especificamente, aquelas que o fazem em presença no espaço público urbano.

\section{A Arte na cidade}

As relações entre arte e espaço urbano são antigas, extensamente discutidas sob várias ópticas distintas. Aparentemente, os enfoques mais comuns ao assunto continuam sendo o da cidade como local de uma visibilidade específica para a obra de arte, por um lado, e o da arte como embelezamento e construção simbólica da paisagem urbana, de outro. O que mais interessa a este texto, porém, é a intervenção artística em espaço urbano, um caso de "presença artística" na cidade bem distinta simples locação de obras em espaços públicos.

9 No original: "The (neo-avantgardist) aesthetic aspiration to exceed the limitations of traditional media, like painting and sculpture, as well as their institutional setting; the epistemological challenge to relocate meaning from within the art object to the contingencies of its context; the radical restructuring of the subject from an old Cartesian model to a phenomenological one of lived bodily experience; and the self-conscious desire to resist the forces of the capitalist market economy, which circulates art works as transportable and exchangeable commodity goods" (KWON, 2002, p.12)

10 No original: "within the situation of postmodernism, practice is not defined in relation to a given medium - sculpture - but rather in relation to the logical operations on a set of cultural terms, for which any medium - photography, books, lines on walls, mirrors, or sculpture itself - might be used" (KRAUSS, 1998, p.41). A primeira publicação do texto data de 1979.

11 Miwon Kwon delineou de três paradigmas de "especificidade" no desenvolvimento histórico da prática site-specific. o paradigma fenomenológico, o paradigma social/institucional e o paradigma discursivo (KWON, ago. 2002).
O termo "intervenção" designa aqui práticas artísticas que se constituem a partir da atuação consciente e deliberada sobre contextos físicos e discursivos específicos. Tais práticas teriam origem no ambiente contestador e experimentalista das "neovanguardas" das artes visuais dos anos sessenta, provavelmente o momento mais radical de crítica e expansão e das fronteiras da arte, intrinsecamente ligado ao contexto de crítica social da época. Em retrospectiva, a pesquisadora Miwon Kwon sintetizou esse momento artístico no seguinte conjunto de elementos:

a aspiração estética (neovanguardista) de exceder as limitações dos meios tradicionais, como pintura e escultura, assim como seu aparato institucional; o desafio epistemológico de deslocar a significação do interior do objeto artístico para as contingências de seu contexto; a reestruturação radical do sujeito, de um velho modelo cartesiano para um fenomenológico de experiência vivida corporalmente; e o desejo autoconsciente de resistir às forças da economia de mercado capitalista, a qual põe em circulação trabalhos de arte como mercadorias transportáveis e trocáveis [...]. (KWON, 2002, p. 12) ${ }^{9}$

A ênfase transgressora das experiências da época afastaria as obras artísticas da investigação formal centrada nos suportes (escultura, pintura, etc.) para a inclusão de diversas outras questões referentes à sociedade e à instituição artística. Aproximandose da cultura popular, da indústria cultural e da contracultura, as artes plásticas passaram a invadir espaços "alternativos" aos locais institucionalmente circunscritos: de um lado, os novos meios de comunicação, documentaçãa, veiculação e circulação de informações e produtos (os media, o cinema independente, o espaço publicitário, o sistema de correios); e de outro, os espaços "externos" das paisagens naturais, da arquitetura e do espaço urbano.

Dentro da situação do pós-modernismo, a prática não é definida em relação a um dado meio escultura — porém mais em relação às operações lógicas em um conjunto de termos culturais, para os quais qualquer meio - fotografia, livros, linhas em paredes, ou a própria escultura — podem ser usados. (KRAUSS, 1998, p.41) 10

Em contraposição à autonomia idealizada do objeto artístico - bem como aos mercados e instituições apoiados neste - várias operações artísticas desde os anos sessenta passaram a usar "obras" para discutir justamente o espaço, a instituição, o sistema social e ideológico relacionados a elas. Em contraposição ao espaço "ideal" e abstrato do museu, surgiu o paradigma de arte "site-specific" - trabalhos criados a partir de situações e locais específicos, ao invés de objetos transportáveis. A noção de "especificidade", por sua vez, sofreu desdobramentos desde suas primeiras experiências, como aponta M. Kwon (ago. 2002): inicialmente, predominaria uma perspectiva mais formal e sensorial dos lugares de intervenção, e com o tempo a "especificidade" adquiriu teor mais cultural e histórico, com obras que passaram a investigar a relação entre produção social dos espaços e da percepção estética ${ }^{11}$.

Conforme mencionado anteriormente, porém, a arte em espaço urbano tem sido empregada nas últimas décadas como parte do processo de estetização e espetacularização da cidade, voltado à constituição de uma imagem e um clima cultural atrativos, por um lado, e à "suspensão" simbólica de contradições sociais e políticas presentes nos espaços, por outro. Nessa situação, o contextualismo site-specific não pode ser compreendido como crítico per se; a "especificidade de sítio" já seria instrumentalizada desde os anos oitenta por processos de requalificação de espaços urbanos, chamada a "contribuir" com a cidade e a "preencher" necessidades sociais, seja como decoração formalista e utilitária ou 
12 Segundo Rosalyn Deutsche, a New Public Art norteamericana dos anos oitenta seria em muitos aspectos a pioneira desse processo. Pensada como contextualista e site-specific, ela se dedicava à criação de espaços em contraposição à tradicional locação "decorativa" de objetos de arte na urbe (DEUTSCHE, 1996, p.19). Mas essas "colaborações" de artistas com arquitetos, urbanistas e governos seriam também estetizantes e "funcionalizantes": produziriam ambientes agradáveis e particularizados, forneceriam mobiliário, drenagem de água, marcação de datas históricas importantes, acentuariam ou conduziriam a percepção do público para algo. Essa arte seria saudada pelo marketing dos promotores de desenvolvimento, críticos de arte e políticos conservadores como "socialmente responsável" por sua contribuição funcional ou estética para os "prazeres do ambiente urbano" (idem, p. 48), tornando-se fator de propaganda de locais urbanos em ascensão. como simbolização de uma identidade cultural fetichizada ${ }^{12}$

Em meio à instrumentalização ideológica ou comercial, torna-se necessário a uma arte urbana crítica evitar conotações simplistas de "democratização" ou "desinstitucionalização" da arte pela simples presença pública, bem como de "enriquecimento" da cidade pela simples presença da arte; seria preciso pensar o espaço urbano como um discurso material e socialmente construído e a arte como um dos agentes da produção desse discurso. A idéia de "produção social do espaço" de Henri Lefebvre colocaria o significado urbano como algo surgido das práticas cotidianas de uso da cidade. Por essa perspectiva, a realização de manifestações artísticas em espaços urbanos poderia ser encarada como uma "prática social relacionada a modos de apropriação do espaço" (PALLAMIN, 2001, p.45) no interior da vida cotidiana. Em sentido semelhante, Michel de Certeau falaria sobre o uso cotidiano do espaço como uma manipulação análoga à operação da linguagem:

\section{[...] da mesma forma como uma figura de retórica é} uma operação feita no interior do sistema lingüístico, podemos dizer que as práticas cotidianas constituem diferentes tipos de operação no interior de um sistema urbanístico, de um sistema econômico, etc., havendo, portanto, certo paralelismo entre ambas. Pois essas práticas são igualmente manipulações, maneiras de utilização da língua, do sistema, perante as relações de força, utilizando-as para contornar o léxico existente, dos objetos, dos lugares de uma sociedade, dos lugares de uma cidade, etc. (CERTEAU, 1985, p.17)

Ao fazer-se presente na cidade, a arte faria parte então do jogo de léxicos urbanos — seja em favor dos usos e discursos dominantes, seja contra estes. Nesse sentido, a habilidade propriamente crítica da arte na cidade estaria ligada a "criações que imaginam novas possibilidades para as práticas espaciais" (PALLAMIN, 2001, p.44-5), atuando em dissonância ao sistema vigente de forças e representações que mantém uma determinada ordem, propondo relações diferenciadas de uso e de e significado. O debate de autores norte-americanos sobre arte pública pensaria esse potencial de crítica em termos de noções agonísticas de democracia e espaço público. R. Deutsche, por exemplo, postularia a arte pública crítica não como uma prática voltada a audiências pré-existentes que ocupa e desenha espaços físicos, mas sim como uma prática que constrói um espaço público, ao se envolver e engajar pessoas em discussões e disputas políticas (DEUTSCHE, 1996, p.288).

Seria possível pensar essa crítica da arte em termos da oposição feita por Michel de Certeau (1994) entre o modelo de ação estratégica e o modelo de ação tática. Orientado à ocupação e organização sistemática de um determinado território, o paradigma "estratégico" postularia um lugar delimitável como seu, a partir do qual se "gerenciam relações com uma 'exterioridade' composta de alvos e ameaças" (CERTEAU, 1994, p.36). O modelo "tático", por sua vez, se refere a um contexto não-idêntico no qual se efetuar uma ação dinâmica e nômade, sem base estática; como explica Pallamin (2001, p.36), seu espaço seria o da alteridade, implicando em "mobilidade conforme as condições do momento e atenção a particulares injunções". Nesse sentido, a inserção crítica da arte na cidade é necessariamente tática: ela tem de mover-se taticamente num campo de alteridade e, com sua ação, introduzir ou revelar alteridade - de demandas, fazeres, representações ou formas sensíveis - no espaço normalmente percebido como "coerente".

Ao mesmo tempo deslocada da "autonomia" do objeto artístico tradicional e deslocada do sistema de utilidade e significado dominantes do cotidiano, a arte poderia em tese constituir momentaneamente espaços táticos de alteridade interior a uma ordem instituída - ou seja, ser o "outro" da realidade dentro desta própria. M. Chauí denominou "contradiscurso" a classe de discursos que se elaboraria dentro de outro discurso de forma a desdobrar as contradições deste (CHAUÍ, 2003, p.23); de maneira análoga, poderíamos considerar então que a potência política da arte na cidade estaria em constituir-se em seu contradiscurso.

\section{Contradiscursos urbanos}

Uma grande variedade operações críticas nos e aos espaços urbanos têm sido elaborados na história recente das artes, muitas das quais já foram largamente estudadas e debatidas. Porém, é possível divisar padrões, recorrências e direcionamentos no que se refere aos meios, às ênfases e ao tipo de envolvimento com que esses contradiscursos têm 
sido constituídos desde os anos oitenta. A título de reflexão, propõe-se a seguir o esboço de quatro direções básicas de intervenção, correlacionáveis e combináveis entre si: a intervenção plástica, a ocupação gráfica, a criação de situações e o agenciamento de mídias e processos.

A ideia de intervenção plástica, em primeiro lugar, visa aqui englobar trabalhos que, através de construções, inserções e subtrações físicas e materiais no espaço urbano, interferem na relação humana com a arquitetura e a paisagem. É provavelmente o tipo mais célebre de arte site-specific, centrando seus meios e alvos na materialidade, na forma e na experiência corporal. Os precedentes desse tipo de operação remontam às experiências minimalistas, nos anos sessenta, de passagem do foco no objeto artístico para o foco no espaço, concomitante à busca de superação do domínio da visualidade contemplativa para a inclusão da vivência do corpo em deslocamento.

Obviamente, como estruturas físicas interferem ou se vinculam aos significados e usos dos locais em que se encontram, intervenções essencialmente plásticas acumulam muitas outras nuances além da forma, e podem visar um campo de ação simbólica e pragmaticamente mais amplo. Algumas obras públicas do artista norte-americano Richard Serra seriam exemplos de uma arte que possibilitaria rearticulações da percepção e dos usos do espaço urbano através de adições escultóricas sem emprego de signos ou quaisquer aparatos mais semanticamente carregados. Uma intervenção como Tilted Arc (1981) — instalação de um imenso plano curvo de aço na Federal Plaza, em Nova York — não seria nem uma investigação formal autônoma e nem uma tentativa de embelezamento. Relacionada a uma leitura do espaço urbano que ultrapassava o âmbito formal, a obra visaria uma rearticulação crítica perante o sítio de intervenção; e, de fato, mostrou-se tão dissonante em relação à função "decorativa" da praça que acabou por ser retirada ${ }^{13}$. Instigadas e embasadas por leituras do espaço, então, intervenções plásticas podem ultrapassar o formalismo e tensionara lógica de visibilidade, organização e uso dos locais nos quais interferem.

Ocupação gráfica, por sua vez, designaria intervenções que se apropriam — muitas vezes clandestinamente - das superfícies visíveis da paisagem urbana como suporte para intervenções pictóricas e/ ou verbais, tratando-as como veículo de mensagens, representações e efeitos gráficos. Este é talvez o meio mais conhecido e corriqueiro de ação no espaço urbano, até por sua relativa acessibilidade de meios e por sua vinculação a práticas socioculturais como a pichação e o graffiti — as quais receberam atenção e acolhimento crescente por parte do mundo da arte desde a década de oitenta, reação que se intensificou na primeira década do século XXI.

Há experiências que trabalham com imagens, signos em espaços urbanos de evidência com a elaboração de outdoors, cartazes ou efetuação de projeções. Mas o meio mais comum e popularmente conhecido desse contradiscurso ainda é o graffiti, com exemplos de "ocupações" que mobilizam muito conscientemente seus locais, tratam questões políticas específicas e discutem a própria cidade, seus usos e territorialidades. É comum que essas mensagens e representações inseridas no campo visual da cidade sejam referentes a temas não relacionados diretamente ao suporte e local onde estão; em certos casos, contudo, elas relacionam-se estreitamente à realidade em que o espaço, edificação ou elemento "ocupado" se insere. Assim, sem alterar materialmente o espaço da cidade - como fariam as "intervenções plásticas" — as ocupações gráficas ocasionam uma recodificação da sua paisagem, com uma perspectiva mais marcadamente semântica.

Criação de situações, por outro lado, se refere à multiplicidade de manifestações efêmeras em espaço urbano, que visam interferir no comportamento cotidiano na cidade não pela manipulação mais ou menos definitiva do espaço físico ou visual, mas por acontecimentos temporários e atividades coletivas que destoem das estruturas de conduta e percepção normatizadas. Uma das principais referências históricas para esse tipo ação crítica estaria no conceito de détournement cunhado pela Internacional Situacionista (1957-1972): o desvio do uso, ordem e significados preestabelecidos da cidade, com ações coletivas que visavam romper com o comportamento passivo da sociedade industrial de consumo e apropriar-se da cidade como espaço de jogo e participação ${ }^{14}$. Mas os fatores como a crítica comportamental e a busca pela interação criativa do público, na verdade, foram características de várias das iniciativas de intervenção mais marcantes surgidas desde a década de sessenta. 
$15 \mathrm{Na}$ caracterização de Hal Foster, esse tipo de trabalho artístico "não põe entre parênteses a arte para um experimento formal ou perceptivo; em vez disso, procura suas filiações em relação a outras práticas (na indústria cultural e em outras partes) [...]. Os artistas ativos nesse trabalho [...] usam as mais variadas formas de produção e modos de abordagem (colagem fototexto, fotografias construídas ou projetadas, videotapes, textos críticos, obras de arte apropriadas, arranjadas ou sucedâneos etc.), e, no entanto, todos eles se parecem no seguinte aspecto: cada um deles trata o espaço público, a representação social ou a linguagem artística na qual ele ou ela intervém tanto como um alvo quanto com uma arma" (FOSTER, 1996, p.139-40).

16 Segundo o próprio artista, a política municipal da cidade em relação aos moradores de rua seria excludente e coercitiva, resumindo-se aos abrigos para sem-teto: lugares às vezes semelhantes a prisões, que não passariam de respostas parciais e provisórias (WODICZKO, 1988, p.54). Em desafio à atitude oficial, o artista proporia com seu veículo algo igualmente parcial e provisório, mas que ao invés de enquadrar e esconder iria aceitar e evidenciar a condição básica de nomadismo da vida desabrigada. Mais que servir a necessidades utilitárias, o veículo destinava-se a ajudar no processo de legitimação de seus usuários como parte da comunidade urbana, chamando atenção para sua labuta diária de movimento e coleta; o fato de que trabalhavam para sua subsistência - como todos os cidadãos - ganharia outra visibilidade (WODICZKO, 1988, p.61-62). Então, além de confrontar-se com os sistemas políticos e econômicos que excluem os sem-teto, esse trabalho subverteria os modos de percepção que os exilam (DEUTSCHE, 1996, p.99)
Podem ser incluídas entre exemplos desse vetor de operações as Interversões do grupo "3 nós 3", na São Paulo dos anos oitenta: atividades como andar em Avenida Paulista de olhos vendados, ensacar esculturas públicas, ou estender grandes faixas de plástico colorido em viadutos na calada da noite - definidas pelo próprio grupo como "atividades públicas que se destinam a colocar em crise a normalidade vigente" (GONÇALVES FILHO, 1981). Um caso particularmente comum de "criação de situações" em espaço urbano em tempos recentes, por outro lado, seriam as performances teatrais de rua que buscam ocasionar interrupções na vida cotidiana, iniciativas marcadas pela interação e o jogo entre artistas e espectadores.

Agenciamento de mídias e processos, por fim, agrupa operações em espaço urbano que trabalhariam com a mobilização de diferentes práticas e espaços de evidência, (sejam as mais novas mídias, seja o espaço, seja os atores presentes nele) procurando intervir diretamente em debates, discursos e processos ligados a estes. Surgidas já no contexto dos anos oitenta de críticas de representações sociais e de debate sobre a noção de espaço público, as intervenções desse tipo tenderiam a compreender a esfera pública como um espaço constituído discursivamente (DEUTSCHE, 1996, p.289) a ser utilizado "como alvo e como arma" de formas múltiplas (FOSTER, 1996) ${ }^{15}$. Uma interessante visada ao tipo de operação que se quer designar aqui é dada pela síntese de características que o artista Krzysztof Wodiczko (polonês radicado nos EUA) fez para o que considerava "arte pública crítica atual" em 1987:

ação crítico-afirmativa na vida cotidiana e suas instituições (educação, design, ambiente, espetáculo e mass-media, etc.); transformação crítica da cultura desde dentro. Colaboração crítica com instituições de mídia massivas e públicas, design e educação em busca de trazer conscientização (ou consciência crítica) em relação à experiência urbana: vencer tempo e espaço em informação, anúncios, quadros de aviso, luminosos, metrôs, monumentos e edifícios públicos, televisão a cabo e canais públicos, etc. Dirige-se ao observador passivo, o habitante alienado da cidade. (WODICZKO, 1987, p.45).

A obra Homeless vehicle(1988-1989), do próprio Wodiczko, seria uma importante referência desse tipo de atividade: nela, o artista empregou o design como mídia crítica para abordar a situação dos sem-teto em Nova York, também problematizando a percepção dos significados e dos processos de reestruturação, capitalização e exclusão social em jogo no espaço urbano. Elaborado para as necessidades nomádicas específicas dos moradores de rua e a partir de um processo de pesquisa e colaboração com estes, o "veículo para semteto" seria ao mesmo tempo utilitário e simbólico: proporcionaria aos envolvidos uma ferramenta de uso da cidade e um espaço de evidência destes como agentes do espaço urbano, problematizando sua condição de invisibilidade social e de sujeição a políticas institucionais coercitivas ${ }^{16}$.

Mais do que uma questão de meios ou fins, a diferença do agenciamento de mídias e processos para as outras direções de contradiscurso aqui propostas é essencialmente processual: trata-se de atividades que articulam variados meios e atores dentro do sistema urbano e social, mas também que tomam essa própria articulação como fator simbólico em si, como parte da manipulação de significados e usos que opera. Isso implicaria numa prática complexa e ramificada de negociação, da qual a "obra" ou acontecimento visível seria apenas um dos produtos; nesse caminho, mais que produzir objetos, ambientes ou ações autônomas, os artistas passariam a agenciar relações no espaço urbano (MOASSAB, 2003). Aproximando-se mais do ativismo político, as intervenções mais "agenciadoras" tenderiam a trabalhar o ambiente urbano como campo de forças, interesses e representações, procurando crescentemente se inserir em processos participativos e coletivos para catalisar relações e debates públicos.

Apresentados esses quatro conjuntos de intervenção urbana, é necessário frisar a consciência de que tal divisão é inevitavelmente redutora, implicando em abrigar sob cada categoria uma multiplicidade de artistas, motivações, concepções e contextos de atuação completamente diferenciados. Ainda assim, acredita-se aqui que esse esboço poderá fornecer uma referência introdutória útil a interessados em intervenções artísticas no espaço urbano. A diferenciação aqui proposta também não exclui a possibilidade de combinações e sobreposições entre os caminhos apontados; projetos cuja intervenção mais visível é predominantemente plástica podem 
estar engajados em processos mais amplos de negociação e representação social, e assim por diante. Assim sendo, "intervenção plástica", "ocupação gráfica", "criação de situações" e "agenciamento de mídias e processos", devem ser encarados menos como categorias que como dimensões de ação.

\section{A normalização da transgressão e os grandes eventos de arte urbana}

Consideradas certas potencialidades e variedades críticas da intervenção artística sobre o espaço urbano, é necessário por fim considerar certas dificuldades que as transformações na cultura e no circuito artístico trariam para a constituição de "contradiscursos urbanos" pela arte, ao colocarem em crise o lugar da crítica e absorverem a transgressão artística como forma institucionalizável e consumível.

Em contraposição ao momento "contestador" dos anos sessenta, as últimas décadas do século $X X$ assistiriam à reinserção das atividades originalmente transgressoras nas instituições e no mercado, formando uma "estética do antiartístico" ${ }^{17}$. Essa legitimação e a apropriação de operações antes subversivas, por sua vez, estariam intrinsecamente ligadas às mudanças que a dimensão cultural sofrera em sua relação com o capitalismo no fim do século - em especial o "alargamento prodigioso daquilo que chamamos de cultura, em virtude da mídia e da informatização da vida diária". (JAMESON, 1994, p.189)

A indústria cultural contemporânea teria se transformado em um "espaço de heterogeneidade, onde se interpenetram arte culta, arte popular de massa e arte comercial" (BUENO, 1999, p.258). A Cultura "generalizada" substituiria as distinções e conflitos interiores à produção cultural por "uma Babel onde habitam todas as formulações estéticas disponíveis" (idem, p.259), englobando igualmente a arte "festiva" e a "subversiva", os cânones históricos, a cultura pop, e manifestações populares, "étnicas" e folclóricas - todas unificadas pelo mercado. O atual uso ubíquo do termo cultura ganharia tons de um consumismo acrítico, no qual a diversidade é um dado positivo na mesma medida em que também é positiva a variedade de ofertas e marcas em um supermercado. O que um consumidor exige de um produto não é problematização, mas eficiência - o que, no caso da cultura, é o prazer, a beleza, a capacidade de entreter ou o respaldo a uma autoimagem de sofisticação. Consolidar-se-ia aí, então, uma situação da Cultura como forma de consumo e controle, na qual a arte seria vista como diversão ou espetáculo e a crítica como "uma série de opiniões a serem consumidas" (FOSTER, 1996, pp.20-21).

Codificadas como formas conhecidas de "arte" e em muito desprovidas de uma vontade política de transformação coletiva do mundo, as aproximações entre arte e vida - seja na publicidade e meios de comunicação, seja na "arte" propriamente dita tenderiam então a acontecer principalmente como espetáculo e consumo, integradas à produção de imagens, aparências e "opiniões". A passagem neovanguardista de uma arte de objetos para uma arte de eventos, documentações e contextos visaria dar ênfase à exibição pública em detrimento do objeto-mercadoria; todavia, o circuito artístico nas últimas décadas transformaria justamente a exibição em sua grande mercadoria.

Com a emergência de novas instituições e formas de gerência fundadas em lógicas de mercado, estabeleceram-se relações muito mais estreitas com o mundo empresarial e passou-se a usar técnicas de marketing e meios de comunicação para transformar a arte em grande atração (BUENO, 1999, pp. 274275). O principal produto vendido e consumido passaria a ser menos as obras do que o "espetáculo" montado a partir delas e em torno delas — fosse a arquitetura do espaço expositivo, o "conjunto temático" de uma exposição ou a "autenticidade" de um espaço urbano. Nesse processo, a percepção ambientalexpandida nas experiências vanguardistas se converteria no oferecimento de uma experiência diferenciada de entretenimento; a figura do curador cresceria e ganharia preponderância como um "organizador de espetáculos", passando a tornar-se por vezes o propositor e indutor de projetos artísticos, enquanto o artista passou a se inserir cada vez mais como um prestador de serviços.

É nesse processo de institucionalização e espetacularização de formas e atividades artísticas, por sua vez, que as práticas de intervenção em espaço urbano começariam a participar nas estratégias de valorização da cidade, sendo assimiladas para a constituição de "identidades" urbanas e/ou de um clima atrativo de "agitação cultural". 
Para concluir o panorama construído neste texto, resta ressaltar que a teia de questões aqui delineada - sobre a despolitização e espetacularização da cidade, sobre a mercantilização e funcionalização da cultura, sobre as formas de crítica e intervenção da arte sobre a cidade e sobre a cooptação e neutralização de práticas e discursos críticos - é de particular importância para a análise de um tipo específico de ocorrência da "arte na cidade" que se estabeleceu a partir dos últimos anos do século $\mathrm{XX}$ : os grandes eventos de arte site-specific em espaços urbanos.

O final do século veria uma proliferação inédita de projetos de arte em espaços não-institucionais, dentre os quais merecem destaque especial os projetos contínuos ligados a uma cidade - o que M. Kwon chamou de city-based international art programs (KWON, ago. 2002). Geralmente agrupados em

18 "Certainly, site-specific art can lead to the unearthing of repressed histories, help provide greater visibility to marginalized groups and issues, and initiate the re(dis) covery of "minor" places so far ignored by the dominant culture. But inasmuch as the current socioeconomic order thrives on the (artificial) production and (mass) consumption of difference (for difference's sake), the siting of art in "real" places can also be a means to extract the social and historical dimensions of these places in order to variously serve the thematic drive of an artist, satisfy institutional demographic profiles, or fulfill the fiscal needs of a city". (KWON, 2002, p.53) Em outro texto, a autora também escreveu: "significantly, the appropriation of site-specific public art for the valorization of urban identities comes at a time of a fundamental cultural shift in which architecture and urban planning, formerly the primary media for expressing a vision of the city, are displaced by other media more intimate with marketing and advertising. [...] Site specificity and public art in this context find new importance because they can supply distinction of place and uniqueness of locational identity, highly seductive qualities in the promotion of towns and cities within the competitive restructuring of the global economic hierarchy" (KWON, ago. 2002). torno de determinados eixos temáticos, tais eventos costumam reunir uma grande quantidade de artistas trabalhando com diferentes locações, espaços públicos e, por vezes, com a população das cidades, capturando a atenção do circuito artístico, da mídia e da intelectualidade. Nesse heterogêneo conjunto de manifestações, pode-se destacar aqui as edições da Documenta de Kassel (Alemanha) ocorridas desde 1987; os eventos do projeto binacional InSite, ocorridos desde 1994 na fronteira entre Tijuana (México) e San Diego (E.U.A); e as quatro edições do projeto Arte/Cidade, ocorridas em São Paulo entre 1994 e 2002

Para autores como Claudia Büttner (2002, p.73), a propagação de eventos de arte em espaço urbano a partir da segunda metade da década de oitenta apontaria menos para uma problematização mais significativa da cidade do que para uma maior apropriação dessas práticas artísticas por interesses de promoção.

\section{[...] aos poucos foi se cristalizando o entusiasmo pela} arte das instalações específicas para um determinado lugar como gênero popular. O primeiro plano foi sendo ocupado pela encenação espetacular do ambiente e não pelo questionamento da realidade preexistente, seja por meio de intervenções sutis, seja pela confrontação com o conteúdo do local. Abriu-se então um mercado formidável: realizadores de festivais e megaeventos, secretarias culturais e muitos empreiteiros de feiras, aeroportos e shopping centers passaram a explorar a eficácia pública da arte em benefício da sua própria imagem e da do local do evento. [...] Atualmente, os setores de marketing conhecem muito bem o valor de mercado da arte em geral. Por isso se valem não apenas da presença de artistas famosos para dar mais brilho aos eventos, mas também aproveitam o fato de que os highlights precisam ter caráter passageiro, devendo ser oferecidos como eventos únicos. (BÜTTNER, 2002, pp.74-75)

Assim, dos museus-espetáculo às grandes exposições temáticas em espaços urbanos, despontariam manifestações cada vez mais difíceis de separar da lógica do consumo e turismo urbano - e, muitas vezes, francamente vinculadas a esta. Deve-se ter em vista que, dentro do quadro de comercialização e competição entre cidades, intervenções site-specific poderiam ser usadas para extrair ou produzir distinção e identidade, fatores aflitivamente procurados no mundo do marketing urbano (KWON, 2002) ${ }^{18}$. Mesmo intervenções voltadas à estranheza e às significações latentes de lugares em situação de suspensão no espaço urbano — os terrain vagues - poderiam também acabar por converter o espaço urbano em um espaço de exposição estetizado, cujas questões políticas ficariam obliteradas. Como alertaria Nelson Brissac Peixoto, curador do Projeto Arte/Cidade, a valorização da "experiência e da deambulação" trazida pelas obras site-specific acabaria "formatando uma pragmática baseada no espetáculo da cidade" ; com a transformação da cidade em local de exibição, "o mapa substitui a obra de arte, a cidade substitui o museu" (PEIXOTO, 2002, p.19).

A rotineirização e apropriação das críticas artísticas, por sua vez, atingiriam mesmo iniciativas mais "agenciadoras" de diálogo e trabalho direto com populações. No fim da década de noventa, já se estabeleceria no circuito mundial das artes um nicho de "ativismo conciliatório", expresso em uma abordagem de questões sociais através de estratégias participativas envolvendo artistas estrangeiros itinerantes trabalhando com comunidades de terceiro mundo. Muitas dessas iniciativas passariam a reproduzir irrefletidamente a fórmula apontada por Kwon (2002, p.146): artista + comunidade + questão social = nova arte pública / crítica. Neste ponto, cabe retomar o alerta de Rancière sobre a tendência do "déficit de política" contemporâneo 
em dar um valor de substituto aos "dispositivos pelos quais a arte entende criar situações e relações novas" - valor que tende a subordiná-los às categorias do consenso. Nessa situação, a tentativa para "ultrapassar a tensão inerente à política da arte" ameaçaria produzir seu contrário: a redução da política ao "serviço social" e a "indistinção ética" (RANCIÈRE, 18 abr. 2005).

Ressalte-se aqui que, no estudo de grandes eventos, é importante que a reflexão sobre intervenção de obras particulares na cidade deve ter seu significado e impacto específico compreendidas no contexto evento cultural ao qual se relaciona. Mais ainda, este mesmo deve ser compreendido em seu impacto geral: ao estabelecer uma teia de discursos curatoriais, ao constituir situações expositivas - com uma infraestrutura física ou informativa de visitação às obras - e ao concentrar a atenção midiática e intelectual, projetos como InSite e Arte/Cidade por si só constituem uma "intervenção ampliada" no espaço urbano, uma situação de evidência diferenciada. Essas grandes exposições constituem-se elas mesmas um campo próprio de visibilidades, interesses e reverberações interferindo na percepção que se possa ter das obras particulares e no estabelecimento de territorialidades da própria cidade. Assim, para considerar a atuação de intervenções da arte no léxico urbano - em qualquer uma das variações enumeradas ao longo deste texto - é necessário atentar para a recodificação que tais eventos por si só já operam nesse mesmo léxico. Pensar os grandes eventos de arte em espaço urbano, por sua vez, implica em atentar para a teia política de forças, discursos e conseqüências que possibilitam e legitimam essas "intervenções ampliadas", considerá-las em sua inserção no sistema de valorações e interesses do circuito artístico e das empresas e instituições que os financiam.

Como campos de visibilidade privilegiados, grandes eventos que lidam com o espaço urbano e seus habitantes existem numa situação ambígua do ponto de vista da construção de críticas na cidade e sobre a cidade: sua escala, sua coesão, suas atividades agregadas - debates, palestras, manifestações - e sua presença em mídia permite um alcance público mais amplo no levantamento de questões políticas relevantes e criação de debates públicos; mas essa mesmas características com frequência trazem exigências espetacularizantes, estetizantes ou assistencialistas para sua viabilização. Nesses casos complexos é necessário, para retomar os termos de Certeau, divisar tanto nuances táticas de crítica quanto nuances estratégicas de espetáculo das atividades que os conformaram.

\section{Considerações finais}

O tom de aporia adotado no panorama construído neste texto não tem pretensão de conduzir a um diagnóstico final e global sobre o tema; pretende apenas levantar e manter em vista aspectos ricos, ambíguos ou contraditórios da relação entre arte, política e cidade a serem considerados tanto em seu estudo quanto em sua prática.

Procurou-se aqui considerar os potenciais críticos particulares da arte no espaço urbano; mas também que, no contexto cultural, social e espacial constituído desde o final do século passado, tais potenciais não impossibilitam a apropriação dessa arte como elemento de reificação e espetacularização da cidade. A atuação crítica do trabalho artístico, afinal, está sujeito à condição dúbia da própria "arte" como espaço diferenciado em nossa sociedade: a mesma instituição "arte" que pode ser apropriada e instrumentalizada para ações novas e socialmente inviáveis no mundo instrumental da vida cotidiana, afinal, é também uma possível moldura estetizante que pode diluir a potência política destas. Embora aparentemente óbvio, é sempre importante ressaltar que não há atuação crítica efetiva sem uma coletividade política, um público disposto a engajar sua consciência.

Visou-se aqui, enfim, menos à caracterização de impasses do que a um vislumbre da multiplicidade e da complexidade de fatores e manifestações com que se pode deparar ao se examinar o jogo entre aspectos táticos e estratégicos, entre criação de dissensos e apropriação por ordens consensuais. Espera-se, sobretudo, ter fornecido aqui alguma contribuição para estudos que partilham do impulso que ocasionou este texto, ou seja: reflexões interessadas na procura contínua de novas e antigas propostas de resistência e dissenso na arte e na cidade.

\section{Referências bibliográficas}

ANÔNIMO. "O urbanismo unitário no fim dos anos 50". Revista Óculum, Campinas, n4, Novembro 1993. 
ARANTES, Otilia Cultura e transformação urbana, In: PALLAMIN, Vera M. (org). Cidade e Cultura: Esfera Pública e Transformação Urbana. São Paulo: Estação Liberdade, 2002.

BUENO, Maria Lúcia. Artes plásticas no século XX: modernidade e globalização. Campinas: Editora da Unicamp, 1999.

BÜTTNER, Claudia. Projetos artísticos nos espaços nãoinstitucionais de hoje. In: PALLAMIN, Vera M. (org). Cidade e Cultura: Esfera Pública e Transformação Urbana. São Paulo: Estação Liberdade, 2002.

CERTEAU, M. Invenção do Cotidiano: artes do fazer. Petrópolis: Ed Vozes, 1994

CERTEAU, M. Teoria e método no estudo das práticas cotidianas. In: Anais do Encontro Cotidiano, cultura popular e planejamento urbano. São Paulo, FAU-USP, 1985 (p. 1-19)

CHAUÍ, Marilena. Cultura e Democracia. São Paulo: Cortez, 2003

CLARK, T.J. "Modernism, postmodernism and steam". October 100, Spring 2002

DEBORD, Guy. Sociedade do espetáculo. São Paulo: Contraponto, 1997.

DEBORD, Guy. "Teoria da deriva". Revista Óculum, Campinas, n4, Novembro 1993.

DEUTSCHE, Rosalyn. Evictions: Art and Spatial Politics. Cambridge: MIT Press, 1996.

ESCOBAR, Ticio. Elogio do Silêncio. A resistência nos tempos do mercado. In: FUNDAÇÃO BIENAL DE SÃO PAULO. 25a Bienal de São Paulo - Iconografias Metropolitanas: Cidades. Catálogo. São Paulo: Fundação Bienal de São Paulo. 2002.

FARIAS Agnaldo C. "De Richard Serra para os arquitetos". Caramelo, nº 7, FAU-USP s.d.

FIORAVANTE, Celso. "Brasmitte vai unir São Paulo e Berlim". Folha de São Paulo, São Paulo, Ilustrada, p. 3, 06 jul. 1996.

FOSTER, Hal. Recodificação: arte, espetáculo, política cultural. São Paulo: Casa Editorial Paulista, 1996.

GONÇALVES FILHO, Antonio. "O plástico dos artistas na avenida". Folha de São Paulo, São Paulo, 11 fev. 1981.

GRAHAM, Dan. Legacies of critical practice in the 1980's. In: FOSTER, Hal. (ed). Discussions in contemporary Culture. Seattle: Bay Press, 1987.

HARVEY, David. A Condição Pós-Moderna. São Paulo: Loyola, 1993.

JACQUES, Paola Berenstein. "Do especular ao espetacular". (resenha). Vitruvius, jun. 2005. Disponível em: http://www.vitruvius.com.br/resenhas/textos/resenha 123. asp. Acesso em 11 set. 2005.

KRAUSS, Rosalind. Sculpture in the expanded field. (1979). In FOSTER, Hal(Ed). The anti-aesthetic: essays on postmodern culture. New York: The New Press, 1998.

KWON, Miwon. For Hamburg: Public Art and Urban Identities. In: Public Art is Everywhere (catálogo).
Hamburg: Kunstverein Hamburg and Kulturbehörde Hamburg, 1997. Disponível em: <http://eipcp.net/ transversal/0102/kwon/en>. Acesso: 13 out. 2005.

KWON, Miwon. One place after another: site-specific art and locational identity. Cambridge: The MIT Press, 2002.

JAMESON, Fredric. Espaço e Imagem: Teoria do Pós Modernismo e outros ensaios. Rio de Janeiro: UFRJ, 1994.

JAMESON, Fredric. "Pós-Modernidade e Sociedade de Consumo". Novos Estudos CEBRAP n 12 , São Paulo, junho de 1985.

MOASSAB, Andréia e REBOUÇAS, Renato. Arte e cidade: construindo territorialidades. In: Anais do / Seminário Arte e Cidade (cd-rom). Salvador: UFBA, 2006.

PALLAMIN, Vera M. Arte Urbana: São Paulo: Região Central (1945-1998): obras de caráter temporário e permanente. São Paulo: Annablume, 2001.

PEIXOTO, Nelson Brissac. Intervenções Urbanas: Arte/ Cidade. São Paulo: SENAC São Paulo, 2002.

RANCIÈRE, Jacques. O dissenso. In: NOVAES, Adauto A crise da razão. São Paulo: Cia. das Letras, 1996, pp. 373-377.

RANCIÈRE, Jacques. "A política da arte e seus paradoxos contemporâneos". Conferência para o Seminário Internacional Estética e Política - São Paulo S/A - práticas estéticas, sociais e políticas em debate, proferida em 18 abr. 2005. URL: http//www. sescsp.org.br/sesd conferencia s/subindex cfm? referencia $=3806 \& 1 \mathrm{l}$ =206\&ParamEnd=9. Acesso: 12 fev. 2006 .

SANTOS, Laymert Garcia. A arte na cidade: entre a deslocalização e o deslocamento. In: PEIXOTO, Nelson Brissac. Arte/Cidade: Cidade sem Janelas(catálogo). São Paulo: Editora Marca D'Água, 1994

SERRA, Richard. Tilted Arc Destroyed. In: SERRA, Richard. Writings/Interviews. Chicago: University of Chicago Press, 1994, pp.193-213.

SOLÀ-MORALES, Ignasi de. Terrain Vague. Quaderns de Arquitetura y Urbanismo, Barcelona, $n^{\circ} 212$, p. 3444, 1995.

SOLÀ-MORALES, Ignasi de. Presente y futuros. La arquitectura en las ciudades. In: AA.V. Presente y futuros. Arquitectura en las grandes ciudades, Barcelona: Collegi Oficial d'Arquitectes de Catalunya / Centre de Cultura Contemporània, 1996.

VAZ, Lilian F., e JACQUES, Paola B. "A cultura na revitalização urbana - espetáculo ou participação?". Espaço \& Debates, São Paulo, v.23, n43- 44, Jan/ dez 2003.

WODICZKO, Krzysztof. Strategies of public address: which media, which public? In: FOSTER, Hal. (Ed) Discussions in contemporary Culture. Seattle: Bay Press, 1987.

WODICZKO, Krzysztof e LURIE, David V. "Homeless Vehicle Project". October, Vol. 47, winter, 1988, pp. 53-67.

ZAERA, Alejandro. La organización material del capitalismo avanzado. Revista Domino. Montevideo, $\mathrm{n}^{\circ} 2$, pp.8-15, 1996. 